\title{
Expert survey on capacity markets in the US: Lessons for the EU
}

\author{
Pradyumna C Bhagwat ${ }^{* 1}$, Laurens de Vries ${ }^{1}$ and Benjamin F. Hobbs $^{2}$ \\ ${ }^{I}$ Faculty of Technology, Policy and Management, Delft University of Technology, Jaffalaan 5, 2628 BX, Delft, The \\ Netherlands \\ ${ }^{2}$ Department of Geography and \& Environmental Engineering and the Environment, Energy, Sustainability \& Health \\ Institute, The Johns Hopkins University, 3400 North Charles Street, Ames Hall 313, MD 21218, Baltimore, USA \\ *Corresponding author, mail: P.C.Bhagwat@tudelft.nl; Telephone: +31 152783963.
}

\begin{abstract}
We present a survey of US capacity market experts with the purpose of drawing lessons for the EU. Of the respondents, $41 \%$ advised EU member states against implementing capacity markets, while the remaining were neutral or provided suggestions for improving capacity markets. Cross-border effects are currently not a concern but may become so in the future. Imports may dampen prices in a capacity market, but neighbouring markets may also experience pressure to implement a capacity market. The capacity markets in the USA were believed to have achieved their goals with respect to reliability, but in an economically inefficient manner.
\end{abstract}

KEYWORDS: adequacy policy, capacity markets, electricity markets, electricity networks. 


\section{Introduction ${ }^{1}$}

The arguments for implementing a capacity market have been described extensively in the literature (Chao and Lawrence, 2009; Cramton et al., 2013; De Vries, 2007; Hobbs et al., 2001; Joskow, 2008a; Nicolosi and Fürsch, 2009; Stoft, 2002). As member states of the European Union are starting to implement capacity markets, learning from other regions with more experience could not only reduce the risk of policy failure but could also help improve the design and implementation of new market mechanisms. While capacity markets have been the subject of debate for more than a decade, there is little consensus on the need for them or their optimal design (Crampton and Stoft, 2006; De Vries and Hakvoort, 2003; Joskow and Tirole, 2007; Joskow, 2008a, 2006a; Neuhoff et al., 2011; Pérez-Arriaga, 2001). Perhaps as a consequence, the market designs for France and the UK are widely different (DECC, 2014; RTE, 2014). The UK's capacity market recently held its first auction, clearing at a lower price than expected and indicating once again the difficulty of design (OFGEM, 2015). Germany, on the other hand, decided not to implement a capacity markets (BMWi, 2015).

Capacity market design in the US has faced a number of issues, such as the role of demand response, whether locational constraints should be imposed, how far forward such markets should be run, and whether separate markets should be created for flexible capacity to back up intermittent renewables. An issue of particular interest to the EU concerns inefficiencies that might arise when wholesale electricity markets with different capacity markets are interconnected or when regions with capacity markets are interconnected with energy-only markets. This could lead to sub-optimal performance of the capacity markets and spillover of benefits or costs to neighbouring markets. There is also a risk that capacity markets might distort cross-border trade and reduce market transparency (Cepeda and Finon, 2011; Elberg, 2014; Gore, 2015; Meyer and Gore, 2015; Tennbakk, 2014; Viljainen et al., 2013). The above-mentioned effects are termed as "seams issues" (US) or "cross-border effects" (EU). Seams issues that may arise with the implementation of capacity markets are currently of much concern in the European Union (ACER, 2013; Finon, 2015; Mastropietro et al., 2015; Newbery and Grubb, 2014; Regulatory Assistance Project, 2013; SWECO, 2014). The objective of this paper is to draw lessons for Europe from the American experience.

\footnotetext{
${ }^{1}$ A preliminary version of this paper was presented at the 38th IAEE International Conference, Antalya 2015.
} 
Over the past decade, three wholesale electricity market regions in northeast United States implemented capacity markets (NYISO, ISO-NE, and PJM). ${ }^{2}$ These markets have differing designs and have evolved over their periods of existence. This evolution includes the creation of separate markets for flexible capacity, geographical definition of market sub-regions, and modifications to market clearing mechanisms (such as use of demand curves). MISO has recently implemented a capacity market. Capacity markets have not been implemented in the southwest region (Southwest Power Pool or SPP). The state of California has imposed a resource adequacy requirement on load serving entities, but has not created a centrally coordinated market to facilitate efficient trading of resources to meet that requirement. California's resource adequacy framework is described in literature by Pfeifenberger et al., (2012), CPUC, (2015), CAISO, (2015)

The main objective for capacity markets is to improve the resource adequacy of the system by maintaining sufficient reserve margins. These margins are calculated from the loss of load probability (LOLE) requirement of the independent system operator (ISO). An underlying assumption is that spot markets by themselves are characterized by market failures for which capacity markets must compensate. The first market failure was the 'missing money problem' (Cramton and Stoft, 2006; Joskow, 2008a; Pfeifenberger et al., 2009; Shanker, 2003). Due to price caps, the absence of shortage ("scarcity") pricing, long averaging periods, or other reasons, energy and ancillary service prices may fail to reflect the full value of power, which in theory would result in inadequate remuneration for investors and underinvestment in capacity. Revenues from capacity markets enable resources with high variable costs that under normal circumstances would be either mothballed or dismantled to remain available. The second market failure is the absence of a longrun contract market that some argue is necessary to induce risk-averse investors to build new, longlived generation capacity. The additional revenues from the capacity market provide a stronger investment signal for new capacity additions.

In the EU, design and implementation of capacity markets are left to the discretion of member states, which means that each member state may have different capacity market designs or mechanisms. Table 1 indicates to what extent capacity mechanisms have been implemented in the member states of the EU. While France and the UK have implemented capacity markets, the German Federal Ministry for Economic Affairs recently released a 'white paper' that rejected implementation of capacity markets in response to discussions with various stakeholders and recommendations from experts $(\mathrm{BMWi}, 2015)$. At the same time, however, the white paper states that there exists broad support for introducing capacity reserves and improving the electricity market design.

\footnotetext{
${ }^{2}$ NYISO: New York - ISO, ISO-NE: ISO New England, PJM: Pennsylvania-New Jersey-Maryland.
} 
Table 1: Status of capacity mechanism implementation in the EU (Based on (ACER, 2013))

\begin{tabular}{|c|c|}
\hline Capacity Mechanism & EU Member States \\
\hline Capacity Market & France, UK \\
\hline Capacity Payment & $\begin{array}{c}\text { Greece, Ireland, } \\
\text { Italy (Capacity market } \\
\text { planned), Portugal, Spain }\end{array}$ \\
\hline Capacity Reserve & $\begin{array}{c}\text { Germany (Under } \\
\text { consideration) }\end{array}$ \\
\hline Strategic Reserve & $\begin{array}{c}\text { Belgium, Finland, } \\
\text { Sweden (Phase-out 2020) }\end{array}$ \\
\hline
\end{tabular}

After a desk review of the four capacity markets in the US, this paper presents a survey of experts with knowledge of the United States electricity sector. The goal of this survey was to provide insight and advice to the EU with respect to selecting, designing, implementing and administering capacity markets in a highly interconnected electricity network, based on the experience with capacity markets in the United States. Emphasis was given to cross-border effects that may arise from implementing capacity mechanisms in interconnected regions. The survey respondents were questioned about such occurrences and their impact as well as how they were dealt with in the US experience. The respondents invited to participate in the survey represented various stakeholders (Details in Section 3).

This paper is structured as follows. Section 2 provides a description of the four capacity markets in the United States followed in Section 3 by a description of the knowledgeable expert survey. The survey results and conclusions are presented in Section 4 and 5 respectively.

\section{Capacity markets in the United States}

The development of competitive wholesale electricity markets has been described in Borenstein and Bushnell, (2000); Brennan et al., (2002); Joskow, (2008b, 2006, 1997); Navigant Consulting, (2013); Sioshansi, (2013). Currently, the United States has seven regional wholesale electricity markets that are administered by independent system operators (ISOs) ${ }^{3}$, namely SPP, ERCOT, MISO, CAISO, ISO-NE, NYISO, PJM (IRC, 2015). Capacity markets have been implemented in the four northeast-Midwest markets of NYISO, PJM, NE-ISO, and MISO ${ }^{4}$. Their performance has been discussed by, among others, Harvey (2005), Harvey et al. (2013), and Spees et al. (2013).

Each region has its own unique capacity market design (see Table 2) and modes of interconnection with neighboring regions. This makes the study of US capacity markets relevant for Europe. As the heterogeneity in US capacity markets provides the context for our survey findings,

\footnotetext{
${ }^{3}$ An illustration of the areas of the ISOs is available at www.ferc.gov/industries/electric/indus-act/rto.asp

${ }^{4}$ MISO: Midcontinent ISO.
} 
we provide a brief overview of the different capacity market designs presently implemented in the United States.

Table 2: Difference in design of various capacity markets in the US (Based on Spees et al., 2013).

\begin{tabular}{|c|c|c|c|c|}
\hline Market & Forward Procurement Period & Auction Process & Procurement & Demand Curve \\
\hline PJM & 3 Years & Uniform price & Mandatory Auction, Bilateral & Sloped \\
\hline NYISO & 1 Year & Uniform price & Mandatory \& Voluntary Auctions, Bilateral & Sloped \\
\hline ISO-NE & 3 Years & Descending clock & Mandatory Auction, Bilateral & Vertical \\
\hline MISO & 1 Year & Descending clock & Mandatory Auction, Bilateral & Vertical \\
\hline
\end{tabular}

\subsection{NYISO: Installed Capacity Market}

The New York Independent System Operator (NYISO) organizes an installed capacity (ICAP) market. Unforced capacity (UCAP) (NYISO, 2013a, 2013b) is offered in a series of auctions by generators. Load-serving entities are obligated to purchase the minimum volume of unforced capacity that has been assigned to them (Harvey, 2005; NYISO, 2013a, 2013b). UCAP is defined as the installed capacity adjusted for availability, as provided by the Generating Availability Data System (GADS) (NYISO, 2013b). Harvey (2005) describes how the UCAP is calculated. The unforced capacity requirement is calculated from the Installed Reserve Margin (IRM) and forecasted peak load (NYISO, 2013b). The IRM, defined as the required excess capacity (presented as percentage of expected peak demand), is established such that the loss-of-load expectation (LOLE) is once in every ten years, or 0.1 day/year. The LOLE represents the probability that the supply would be lower than demand, expressed in time units. In NYISO, 'days/year' are used (Čepin, 2011)).

Mandatory spot auctions for capacity are conducted once a year for the coming year. In these auctions, supply-side bids of capacity are cleared against a sloping demand curve. The parameters of the sloping demand curve are reviewed every three years. The ISO contracts the required capacity from the capacity market on behalf of load serving entities (LSEs), the cost of which is recovered from the customers as an additional charge. NYISO has defined two six-month capability periods during which it tests the maximum generation output of parties that have sold capacity credits: a Summer capability period (May 1st - Oct 31st) and a Winter capability period (Nov 1st April 30 ${ }^{\text {th }}$ ) (NYISO, 2014). Market parties are allowed to correct their positions in capability-period auctions and again in monthly spot auctions. Imports are allowed to bid into the capacity market, provided that they adhere strictly to rules regarding transmission capability, electricity market bidding, and availability (NYISO, 2013b). Market parties are also allowed to conclude bilateral 
contracts. A detailed description of the market rules is available (NYISO, 2013b; Spees et al., 2013).

\subsection{PJM: Reliability Pricing Model}

The PJM ISO administers an area covering parts of thirteen states and the District of Columbia. The capacity market in this region is called the Reliability Pricing Model (RPM). RPM divides the region into Locational Deliverability Areas (LDAs) that reflect the demand and supply conditions in different locations.

The RPM is a three-year forward capacity market (Cramton and Stoft, 2006). In the first step, mandatory three-year forward base residual auctions (BRA) are conducted. The suppliers' bids are cleared against a sloping demand curve known as the variable resource requirement (VRR). The shape of the VRR depends upon the cost of new entry (CONE) and the administratively set reliability requirement value (Bowring, 2013a, 2013b; Hobbs et al., 2007; PJM, 2013). The BRA is followed by incremental auctions (IA) that are conducted to allow market parties to adjust their positions if required.

The load serving entities (LSE) are also allowed to meet their reliability requirement via selfsupply as well as bilateral contracts with generators. As in the NYISO-ICAP, imports are allowed to participate in capacity markets provided they comply with all PJM requirements (as approved by FERC). PJM has recently proposed capacity performance rules (PJM, 2014). Detailed description of the PJM-ICAP is available in (Bowring, 2013b; Hobbs et al., 2007; PJM, 2013; Spees et al., 2013).

\subsection{ISO-NE: Forward Capacity Market}

The New England ISO covers six states. The ISO-NE initially implemented an ICAP market in 1998. In 2002, deficiencies in the market design were identified by FERC. After much deliberation and negotiation, ISO-NE transitioned from ICAP to a Forward Capacity Market (FCM) in 2008 by conducting an auction for year 2010 (Benedettini, 2013; ISO New England Inc., 2015).

Similar to PJM-RPM, the ISO-NE FCM is a three-year forward market but with a vertical demand curve that has a price cap and floor. The resource adequacy requirement is calculated based on a LOLE of 0.1 day per year. The FCM employs a descending clock auction unlike other capacity market designs. Imports are allowed to participate in the FCM provided they comply with all FERC-approved requirements.

In the FCM, a three-year ahead forward capacity auction (FCA) is initially conducted followed by annual and monthly reconfiguration auctions in order to allow market parties to make 
adjustments. The design of the FCM is described in detail in Benedettini, (2013); ISO New England Inc., (2015), 2014a, 2014b; Spees et al., (2013). The market is presently undergoing a redesign process based on findings of the Strategic Planning initiative (ISO New England Inc., 2014c).

\subsection{MISO: Planning Resource Auction}

The Midcontinent ISO introduced the Planning Resource Auction (PRA) in 2013 to replace its Voluntary Capacity Auction (VCA). Two types of auctions are conducted. Initially, the PRA is a sealed-bid auction for the upcoming year in order to provide a clearing price for each of the local resource zones. Subsequent transitional auctions allow market participants to adjust their positions (MISO, 2013). The PRA is held two months prior to the beginning of the planning year.

The planning reserve margin is set by MISO to achieve a LOLE of 0.1 day per year. The MISO region is divided into Local Resource Zones (LRZ) to ensure sufficient capacity in each geographic zone. The PRA utilizes a vertical demand curve. One of the recommendations of the 2013 State of the Market Report is to implement a sloped demand curve similar to the PJM RPM system (Potomac Economics, 2014).

External resources are allowed to participate in the PRA provided that they meet MISO's FERC-approved requirements, including the must-offer obligation. Detailed description of the MISO PRA is available in MISO, (2015 and 2013); Potomac Economics, (2014); Spees et al., (2013).

\section{Expert Survey}

The main reason for undertaking a survey was to gain a multi-dimensional understanding of the performance of capacity markets in the United States. Considering developments in the EU, the survey is intended to provide insights that may assist the various stakeholders in the European Union with the design and operation of capacity markets.

We survey a broad range of electricity sector experts. The survey was conducted anonymously and the respondents included experts from the electricity industry, market operators, government/regulatory agencies, academia, and consulting firms (see Figure 1); respondents are weighted toward consultants and evenly divided among the rest. The survey was conducted between November 17, 2014 and November 30, 2014. The total number of participants that completed the survey was 22 . 


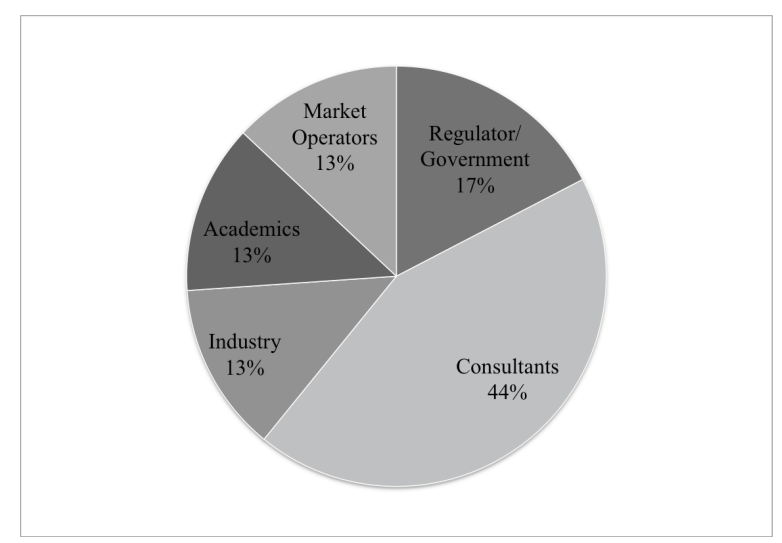

Figure 1: Share of participant's profession

The survey focused on the overall impact of capacity markets with an eye toward providing expert advice to the member states of the European Union. Participants were asked 15 open-ended questions in the form of an online questionnaire. The list of survey questions is provided in the Appendix and our summary analysis of the results follows

\section{Results}

In this section we present the results of the expert survey. This section is divided into two parts: first, insights from the experience with capacity markets in the United States and second, advice to the member states of the European Union.

\subsection{Insights from US capacity markets}

In this section we summarize the responses of the experts on the impact of implementing capacity markets. We present the key areas of concern highlighted by the respondents. This is followed by insights into the performance of capacity markets in terms of their effectiveness in achieving policy goals, impacts on consumers, and cross-border effects arising from interconnection with neighboring regions.

\subsubsection{General Concerns}

The respondents identified some issues of concern with regard to the capacity markets. We order them here according to the frequency of their mentions. The first issue, mentioned by $36 \%$ of the respondents, is the differing designs of neighboring capacity markets, including the mismatch in capacity auction time frames. For example, some capacity markets clear three years ahead while others one year ahead. This issue was also identified by Harvey et al. (2013). Second, the continuous changes in administrative rules in recent years have increased uncertainty and regulatory risk for investors (mentioned by 14\%). The third issue (also mentioned by 14\%) concerns the 
exercise of market power, including bidding above marginal cost and then "double dipping". This is the practice of selling capacity credits and then exporting the power from the same generator to a neighboring market with higher prices. The fourth issue (mentioned by $10 \%$ ) is the uncertainty regarding the availability of the generation capacity that has sold credits under actual scarcity conditions. As remuneration from the capacity market is not linked to performance under scarcity conditions, a concern is that some of the generators that have received capacity payments may not be able to honor their commitments during a scarcity event. This could be a special concern with nontraditional resources, such as demand response.

\subsubsection{Capacity market performance}

The experts generally contend that the capacity markets have achieved the goals of providing the required reserve margin, but in an economically inefficient way (54\% agreed, 23\% disagreed, and $23 \%$ had no opinion). In fact, the regions that have implemented capacity markets have achieved their reliability goals. For example, based on Base Residual Auction results for 2007/2008 through 2017/2018, the PJM-RPM was able to clear adequate capacity and meet reserve targets. This is partly due to the addition of a significant increase in new gas-based capacity. Several respondents suggested that capacity markets lead to excess generation capacity at the cost of the consumers.

In theory, price caps in wholesale electricity markets, used to mitigate market power in the US (FERC, 2014; Wilson, 2000), could adversely affect the incentive to invest in new capacity (Joskow and Tirole, 2007). Nevertheless, since required reserve margins are observed, capacity markets have been effective in achieving their adequacy goals compensating for the 'missing money' problem. However, because these capacity markets were implemented in electricity markets that already had surplus capacity (Spees et al., 2013), it is difficult to determine up to what extent the capacity markets were instrumental in achieving or maintaining the reserve margin levels.

\subsubsection{Consumer benefits}

The introduction of capacity markets has not led to an increase in consumer benefit, according to the respondents, as any potential benefit of the increased supply on electricity prices is offset by the additional costs arising from the capacity market itself. These costs appear to be mainly due to a higher reserve margin than would be economically optimal. Moreover, with respect to energy security, the availability of the additional generation resources remains uncertain. Some respondents cited the disconnection between capacity remuneration and scarcity performance as the reason for these concerns. 
There may be difference in calculating the value of capacity credits for renewable resources in different market regions. A higher capacity credit could result in greater revenues from the capacity market for the renewable generators. According to the survey, $41 \%$ respondents agreed that differences in calculating capacity credits could have an impact on capacity market performance, $23 \%$ were of the opinion that there is no or minor impact, and $36 \%$ had no opinion. The results indicate that it is conceivable for the renewable generators to take advantage of differences in accounting of RES capacity in different regions by operating on the market that provides them with the best possible return, which might not be the same as the market where their production would be most valuable. Moreover, allocating a high volume of capacity credits to generators of variable renewable energy could negatively impact capacity market performance by driving down market prices, thereby reducing its effectiveness in providing incentive for investment in new generation capacity.

\subsubsection{Cross-border effects}

According to $28 \%$ of the respondents, cross-border effects currently are not considered a major concern in the US compared to other identified challenges. This appears to be due to the fact that so far, the regions under consideration have adequate reserve margins. However, cross-border effects are considered a potential future concern, when uneven distribution of generation resources due to the retirement of older coal-based generating units, in part due to the USEPA Clean Power Plan (USEPA, 2014), may exacerbate the free-ridership issue.

According to the survey results, 36\% respondents opined that permitting imports to participate in the capacity markets would have a positive impact on the importing market (provided that regulations ensure a level playing field), as imports could reduce the overall system costs and may also encourage investment in merchant lines in regions of congestion; $28 \%$ were of the opinion that imports could have adverse effects and $36 \%$ offered no opinion on this issue.

Possible seams issues in the United States can be illustrated with a case mentioned in the survey result. Seams issues were observed between the PJM region, which at the time had implemented a capacity market, and the MISO region, which at that time had not implemented a capacity market. Competitive resource providers from the MISO region had greater incentives to offer their resources to the PJM-RPM than to MISO's energy-only market. Allowing these imports to operate in the capacity market by PJM dampened capacity prices under the RPM and increased risk to resource adequacy in MISO. At the same time, concerns were raised regarding the actual availability of these resources when required during scarcity conditions due to possible transmission constraints (such as a mismatch in the calculation of transmission capacity between the two regions 
by the ISOs) and curtailment during emergencies. The survey respondents noted that the need to reduce incentives for generators to export was a key driver in implementing a capacity market in the MISO region.

\subsection{Advice to the EU}

The survey results offer little support for the implementation of capacity markets by the EU member states. There is a clear preference towards depending on energy-only market to provide price signals for adequate investment. The respondents were asked directly, "As countries in EU begin to roll out capacity mechanisms, what advice might you offer to them regarding implementation of capacity markets / mechanisms?" In response, $41 \%$ of the experts surveyed advised the EU not to implement capacity markets and 5\% had no opinion. All of the respondents (except the 5\% with no opinion) provided advice about implementing capacity market. We present the most commonly mentioned suggestions below.

In the event that capacity markets are implemented, the operators should ensure consistent and transparent rules right from the beginning, with minimum modifications once the capacity market is operationalized. This is crucial because administrative conduct can have a strong impact on the capacity market performance. Second, if importers are allowed to participate in capacity markets, it is important to have common definitions for capacity products among different regions. Third, the remuneration for capacity should be linked to the resource provider's performance during scarcity periods, when in fact the capacity is most required. Finally, the sloping demand curve for capacity market clearing that is already being utilized in two (NYISO and PJM) capacity markets in the United States is highly recommended. 


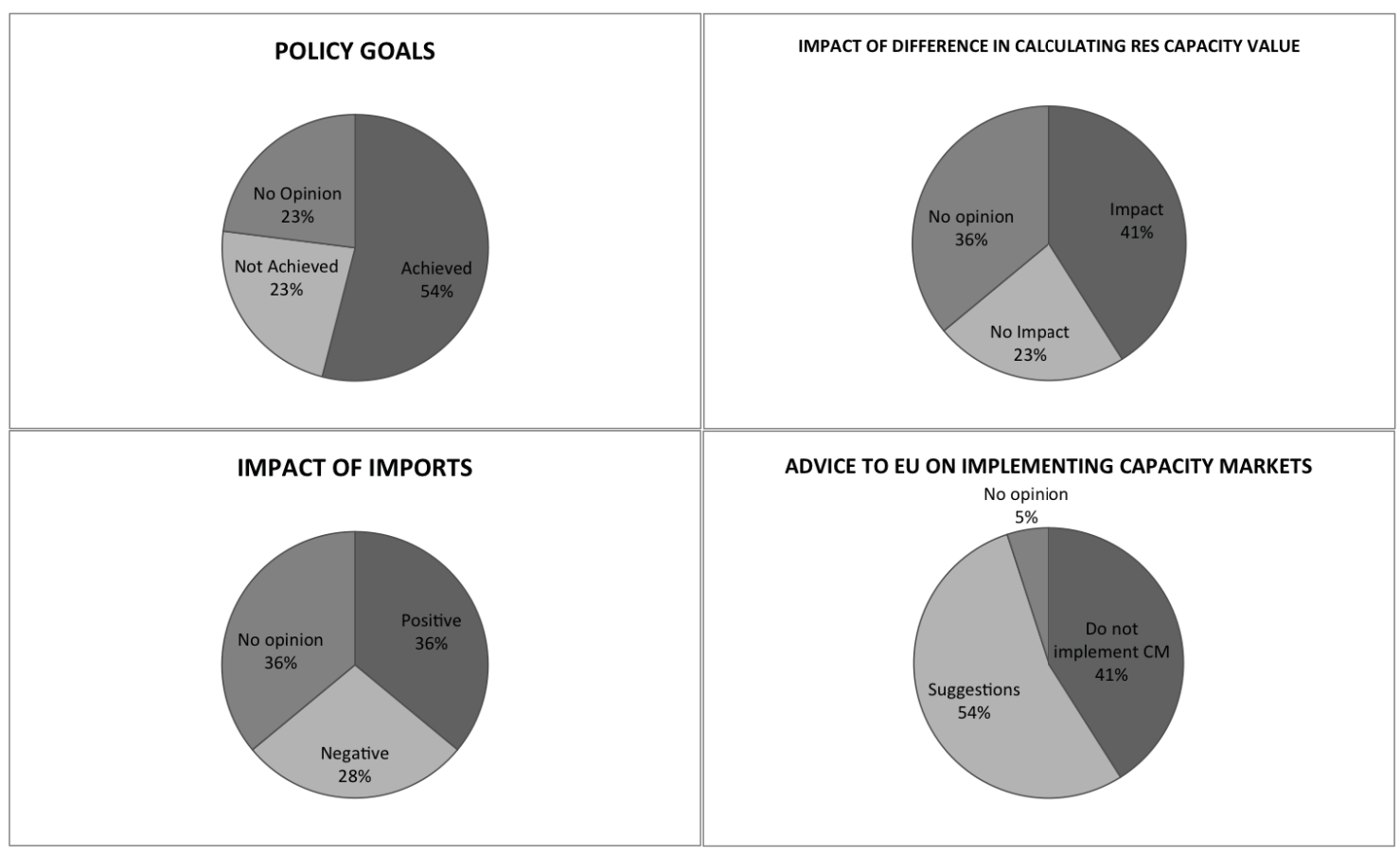

Figure 2: key survey results

\section{Conclusions}

Based on our survey, US experts generally recommend the use of energy-only markets over capacity markets. If a capacity market were to be implemented in the EU, the respondents recommend consistent and transparent rules, common definitions for capacity products, remuneration of providers based on performance during conditions of scarcity, and the use of a sloping demand curve for capacity market clearing.

Another relevant finding for Europe was that in cases when a capacity market allowed generators from neighboring areas to sell capacity in its market, capacity prices were dampened. This 'capacity migration' put pressure on the exporting regions to implement a capacity market as well. The respondents did not view the seams issues as a pressing concern in the US at present, but it was recognized as a potential future issue.

The key concerns about the US capacity markets that emerged from the survey were uncertainty regarding the availability of generation resources that clear the capacity market during scarcity hours, a mismatch of capacity auction time frames, opportunities to exercise market power, and regulatory uncertainty associated with changes to market rules. According to the survey respondents, capacity markets in the United States achieve their goals with respect to reliability, but they do so in an economically inefficient manner because they tend to lead to excess generation capacity. As a result, the implementation of capacity markets has not benefited consumers in the form of lower overall consumer costs. 


\section{Acknowledgments}

The authors would like to thank all the experts who took part in this survey for their time and valuable insights. Pradyumna Bhagwat has been awarded an Erasmus Mundus Joint Doctorate Fellowship. The authors would like to express their gratitude towards all partner institutions within the program as well as the European Commission for their support.

\section{References}

ACER, 2013. Capacity remuneration mechanisms and the internal market for electricity.

Benedettini, S., 2013. PJM and ISO-NE forward capacity markets: a critical assessment. Milan.

BMWi, 2015. An electricity market for Germany's energy transition: White Paper by the Federal Ministry for Economic Affairs and Energy. Berlin.

Borenstein, S., Bushnell, J., 2000. Electricity Restructuring: Deregulation or Reregulation? Regulation 23.

Bowring, J., 2013a. Capacity Markets in PJM. Econ. Energy Environ. Policy 2.

Bowring, J., 2013b. The evolution of the PJM capacity market: Does it address the revenue sufficiency problem?, in: Sioshansi, F. (Ed.), Evolution of Global Electricity Markets. Elsevier.

Brennan, T.J., Palmer, K., Martinez, S., 2002. Implementing electricity restructuring: Policies, potholes, and prospects. Environ. Resour. Econ.

CAISO, 2015. California ISO - Reliability requirements [WWW Document]. URL https://www.caiso.com/planning/Pages/ReliabilityRequirements/Default.aspx ～(accessed 7.2.15).

Cepeda, M., Finon, D., 2011. Generation capacity adequacy in interdependent electricity markets. Energy Policy 39, 3128-3143.

Čepin, M., 2011. Assessment of Power System Reliability: Methods and Applications. Springer Science \& Business Media.

Chao, H., Lawrence, D.J., 2009. How capacity markets address resource adequacy, in: 2009 IEEE Power \& Energy Society General Meeting. IEEE, pp. 1-4.

CPUC, 2015. California Public Utilities Commission [WWW Document]. URL http://www.cpuc.ca.gov/puc/ (accessed 7.2.15).

Crampton, P., Stoft, S., 2006. The convergence of market designs for adequate generating capacity with special attention to the CAISO's resource adequacy problem. Berkeley, California, White Pap. Electr. Overs. Board.

Cramton, P.C., Ockenfels, A., Stoft, S., 2013. Capacity Market Fundamentals. Econ. Energy 
Environ. Policy 2, 27-46.

Cramton, P.C., Stoft, S., 2006. The convergence of market designs for adequate generating capacity with special attention to the CAISO's resource adequacy problem. MIT Center for Energy and Environmental Policy Research.

De Vries, L.J., 2007. Generation adequacy: Helping the market do its job. Util. Policy 15, 20-35.

De Vries, L.J., Hakvoort, R.A., 2003. The Question of Generation Adequacy in Liberalised Electricity Markets, in: IAEE International Conference. Milano, Prague.

DECC, 2014. The Capacity Market Rules 2014: Presented to Parliament pursuant to section 41(9) of the Energy Act 2013. London.

Elberg, C., 2014. Cross-border effects of capacity mechanisms in electricity markets. Institute of Energy Economics at the University of Cologne (EWI).

FERC, 2014. Price Formation in Organized Wholesale Electricity Marketsts. Washington DC.

Finon, D., 2015. Capacity Mechanisms and Cross-Border Participation: The EU wide approach in question.

Gore, O., 2015. IMPACTS OF CAPACITY REMUNERATIVE MECHANISMS ON CROSSBORDER TRADE. Lappeenranta University of Technology.

Harvey, S., 2005. ICAP Systems in the Northeast: Trends and Lessons.

Harvey, S.M., Hogan, W.W., Pope, S.L., 2013. Evaluation of the New York Capacity Market.

Hobbs, B.F., Hu, M.-C., Inon, J.G., Stoft, S.E., Bhavaraju, M.P., 2007. A Dynamic Analysis of a Demand Curve-Based Capacity Market Proposal: The PJM Reliability Pricing Model, in: IEEE Transactions on Power Systems. pp. 3-14.

Hobbs, B.F., Iñón, J., Stoft, S.E., 2001. Installed Capacity Requirements and Price Caps. Electr. J. $14,23-34$.

IRC, 2015. IRC [WWW Document]. URL http://www.isorto.org/Pages/Home (accessed 2.2.15).

ISO New England Inc., 2014a. ISO New England Manual for the Forward Capacity Market (FCM) Manual M-20.

ISO New England Inc., 2014b. Overview of New England's Wholesale Electricity Markets and Market Oversight.

ISO New England Inc., 2014c. 2014 Regional Electricity Outlook.

ISO New England Inc., 2015. ISO-NE Website [WWW Document]. URL http://www.iso-ne.com/ (accessed 2.2.15).

Joskow, P., Tirole, J., 2007. Reliability and competitive electricity markets. RAND J. Econ. 38, 6084.

Joskow, P.L., 1997. Restructuring, Competition and Regulatory Reform in the U.S. Electricity Sector. J. Econ. Perspect. 11, 119-138. 
Joskow, P.L., 2006a. Competitive Electricity Markets And Investment In New Generating Capacity, in: Helm, D. (Ed.), The New Energy Paradigm. Oxford University Press.

Joskow, P.L., 2006b. Markets for power in the United States: An interim assessment. Energy J. 27, $1-36$.

Joskow, P.L., 2008a. Capacity payments in imperfect electricity markets: Need and design. Util. Policy 16, 159-170.

Joskow, P.L., 2008b. Lessons Learned from Electricity Market Liberalization. Energy J.

Mastropietro, P., Rodilla, P., Batlle, C., 2015. National capacity mechanisms in the European internal energy market: Opening the doors to neighbours. Energy Policy 82, 38-47.

Meyer, R., Gore, O., 2015. Cross-border effects of capacity mechanisms: Do uncoordinated market design changes contradict the goals of the European market integration? Energy Econ. 51, 920.

MISO, 2013. Business Practice Manual Resource Adequacy Planning Years 2013 and beyond.

MISO, 2015. MISO Website [WWW Document]. URL https://www.misoenergy.org/ (accessed 2.2.15).

Navigant Consulting, 2013. Evolution of the Electric Industry Structure in the U.S. and Resulting Issues.

Neuhoff, K., Hobbs, B.F., David Newbery, 2011. Congestion Management in European Power Networks, Criteria to Assess the Available Options. Berlin.

Newbery, D., Grubb, M., 2014. The Final Hurdle?: Security of supply, the Capacity Mechanism and the role of interconnectors. Cambridge Working Papers in Economics.

Nicolosi, M., Fürsch, M., 2009. The Impact of an increasing share of RES-E on the Conventional Power Market — The Example of Germany. Zeitschrift für Energiewirtschaft 33, 246-254.

NYISO, 2013a. About NYISO [WWW Document]. URL http:/www.nyiso.com/public/about nyiso/ understanding the markets/capacity market/index.jsp

NYISO, 2013b. NYISO Installed Capacity Manual. Rensselaer, NY.

NYISO, 2014. NYISO - Frequently Asked Questions [WWW Document]. URL http://www.nyiso.com/public/markets_operations-services-customer_support-faq-index.jsp (accessed 9.18.15).

OFGEM, 2015. Annual Report on the Operation of the Capacity Market. London.

Pérez-Arriaga, I.J., 2001. Long-term reliability of generation in competitive wholesale markets: a critical review of issues and alternative options, 2006-08-11]. http://www. iit. upcomillas. es/docs/ ....

Pfeifenberger, J., Spees, K., Schumacher, A., 2009. A comparison of PJM's RPM with alternative energy and capacity market designs. 
Pfeifenberger, J.P., Spees, K., Newell, S.A., 2012. Resource Adequacy in California Options for Improving Efficiency and Effectiveness.

PJM, 2013. Reliability Pricing Model [WWW Document]. URL http://www.pjm.com/markets-andoperations/rpm.aspx

PJM, 2014. PJM Capacity Performance Updated Proposal.

Potomac Economics, 2014. 2013 State of the market report for the MISO electricity markets.

Regulatory Assistance Project, 2013. Capacity Markets and European Market Coupling - Can they Co-Exist?

RTE, 2014. French capacity market. Report accompanying the draft rules. Réseau de Transport D’Électricité, Paris.

Shanker, R., 2003. Comments on Standard Market Design: Resource Adequacy Requirement. Federal Energy Regulatory Commission.

Sioshansi, F. (Ed.), 2013. Evolution of Global Electricity Markets, 1st Edition | Fereidoon Sioshansi | ISBN 9780123978912, 1st ed. Elsevier.

Spees, K., Newell, S.A., Pfeifenberger, J.P., 2013. Capacity Markets - Lessons Learned from the First Decade. Econ. Energy Environ. Policy 2.

Stoft, S., 2002. Power System Economics - Designing Markets for Electricity. IEEE Press, WileyInterscience. Press.

SWECO, 2014. Capacity Markets in Europe: Impacts on Trade and Investments.

Tennbakk, B., 2014. Participation of cross-border capacity in capacity mechanisms.

USEPA, 2014. Clean Power Plan Proposed Rule [WWW Document]. URL http://www2.epa.gov/carbon-pollution-standards/clean-power-plan-proposed-rule (accessed 3.13.15).

Viljainen, S., Makkonen, M., Gore, O., Kuleshov, D., Vasileva, E., 2013. Cross-border electricity trade between the Nordic 'energy-only' market and the Russian capacity-based market.

Wilson, J.F., 2000. Scarcity, Market Power, and Price Caps in Wholesale Electric Power Markets. Electr. J. 13, 33-46.

\section{APPENDIX}

Table 3: List of survey questions

\begin{tabular}{|c|l|}
\hline Sr. No. & \multicolumn{1}{|c|}{ Questions } \\
\hline 1 & $\begin{array}{l}\text { What are the biggest challenges faced by the market participants in the US (or your } \\
\text { region) with regard to the seams issue due to capacity markets? }\end{array}$ \\
\hline
\end{tabular}




\begin{tabular}{|c|c|}
\hline 2 & According to you, how can these seams challenges be better managed? \\
\hline 3 & $\begin{array}{l}\text { Do the ISOs in the US (or your region) have mechanisms to monitor and mitigate } \\
\text { unforeseen seams issues? (If yes, please describe) }\end{array}$ \\
\hline 4 & $\begin{array}{l}\text { In your experience, has implementation of a capacity market in one region caused a } \\
\text { neighbouring region to implement capacity mechanisms to counter negative spill } \\
\text { overs? Please provide examples (reference appreciated) }\end{array}$ \\
\hline 5 & $\begin{array}{l}\text { As countries in EU begin to roll out capacity mechanisms, what advice might you offer } \\
\text { to them regarding implementation of capacity markets / mechanisms? }\end{array}$ \\
\hline 6 & $\begin{array}{l}\text { What were the goals of implementing capacity markets in the US (or in your region) } \\
\text { and have they been achieved? Please elaborate. }\end{array}$ \\
\hline 7 & $\begin{array}{l}\text { In your opinion, have implementation of capacity markets led to an increase in security } \\
\text { of supply and higher level of available capacity in regions implementing capacity } \\
\text { markets? Please give reasons for your answer. (Any reports or links that you could } \\
\text { bring to our attention would be appreciated) }\end{array}$ \\
\hline 8 & $\begin{array}{l}\text { If your answer to the above question is yes, has any tendency of free riding by a } \\
\text { neighbouring region (where, consumers from interconnected regions attain higher } \\
\text { security of supply without paying for it, due to the higher available capacity in the } \\
\text { region with a capacity market that may delist and offer itself in the other market) been } \\
\text { observed? Please provide an example if possible. (Reports or links appreciated) }\end{array}$ \\
\hline 9 & $\begin{array}{l}\text { If you agree that free riding occurs, has the free-riding on the security of supply led to a } \\
\text { rise in plant retirements (and/or mothballing) in these neighbouring market zones } \\
\text { (without capacity mechanisms)? What is your opinion on possible exacerbation of the } \\
\text { "missing money problem" in these energy-only markets due to availability of cheap } \\
\text { imports? }\end{array}$ \\
\hline 10 & $\begin{array}{l}\text { In an interconnected system, has the implementation of capacity markets had any } \\
\text { impact on the wholesale electricity prices in neighbouring regions? If yes, what were } \\
\text { these effects? }\end{array}$ \\
\hline 11 & $\begin{array}{l}\text { After the implementation of a capacity market, has a shift in investment towards the } \\
\text { region with a capacity market occurred? If yes, how strongly has this shift affected } \\
\text { investments in neighbouring regions? Please provide an example. (Reference } \\
\text { appreciated). }\end{array}$ \\
\hline 12 & $\begin{array}{l}\text { How has allowing imports to bid on the capacity market affected the overall } \\
\text { performance of capacity market and the electricity market as a whole? }\end{array}$ \\
\hline
\end{tabular}




\begin{tabular}{|c|l|}
\hline 13 & $\begin{array}{l}\text { What is your opinion on the risk of imports committed on the capacity market not } \\
\text { being able to deliver and honour their contracts when required, due to regulatory } \\
\text { uncertainty such as suspension of market rules? If such a situation has occurred in your } \\
\text { knowledge, please provide example. (Reference appreciated) }\end{array}$ \\
\hline 14 & $\begin{array}{l}\text { In interconnected regions both having capacity markets, would differences in } \\
\text { calculation of capacity credits for renewables affect the effectiveness of the capacity } \\
\text { market performance? (With renewables committing to a market providing a higher } \\
\text { capacity credit value). Please elaborate and provide your opinion }\end{array}$ \\
\hline 15 & $\begin{array}{l}\text { We welcome further remarks and opinions from you on the seams-issues caused by the } \\
\text { implementation of capacity markets. }\end{array}$ \\
\hline
\end{tabular}

